Portland State University

PDXScholar

$5-1-2007$

\title{
Non-thiol reagents regulate ryanodine receptor function by redox interactions that modify reactive thiols
}

\author{
Benjamin S. Marinov \\ Rotimi O. Olojo \\ Ruohong Xia \\ Jonathan J. Abramson
}

Follow this and additional works at: https://pdxscholar.library.pdx.edu/phy_fac

Part of the Physics Commons

Let us know how access to this document benefits you.

\section{Citation Details}

Marinov, B., Olojo, R., Xia, R., \& Abramson, J. (2007). Non-thiol reagents regulate ryanodine receptor function by redox interactions that modify reactive thiols. Antioxidants \& Redox Signaling, 9(5), 609-621.

This Article is brought to you for free and open access. It has been accepted for inclusion in Physics Faculty Publications and Presentations by an authorized administrator of PDXScholar. Please contact us if we can make this document more accessible: pdxscholar@pdx.edu. 


\title{
Original Research Communication
}

\section{Non-Thiol Reagents Regulate Ryanodine Receptor Function by Redox Interactions That Modify Reactive Thiols}

\author{
BENJAMIN S. MARINOV, ${ }^{1}$ ROTIMI O. OLOJO,${ }^{1}$ RUOHONG XIA, ${ }^{2}$ \\ and JONATHAN J. ABRAMSON ${ }^{1}$
}

\begin{abstract}
The $\mathrm{Ca}^{2+}$ release channel (CRC) from sarcoplasmic reticulum (SR) is rich in thiol groups, and their oxidation/reduction by thiol reagents activates/inhibits the CRC. Most channel regulators are not thiol reagents, and the mechanism of their action is illusive. Here the authors show that many channel activators act as electron acceptors, while many channel inhibitors act as electron donors in free radical reactions. The channel activator, caffeine, and the CRC inhibitor, tetracaine, are shown to interact competitively, which suggests that there exists a common site(s) on the CRC, that integrates the donor/acceptor effects of ligands. Moreover, channel activators shift the redox potential of reactive thiols on the ryanodine receptor $(\mathrm{RyR})$ to more negative values and decrease the number of reactive thiols, while channel inhibitors shift the redox potential to more positive values and increase the number of reactive thiols. These observations suggest that the non-thiol channel modulators shift the thiol-disulfide balance within CRC by transiently exchanging electrons with the $\mathrm{Ca}^{2+}$ release protein. Antioxid. Redox Signal. 9, 609-621.
\end{abstract}

\section{INTRODUCTION}

$\mathbf{T}$ HE SARCOPLASMIC RETICULUM (SR) is an intracellular organelle that controls the contractile state of muscle by regulating the $\mathrm{Ca}^{2+}$ concentration in the cytosol. By hydrolysis of ATP, the SR actively accumulates $\mathrm{Ca}^{2+}$ into its lumen, which leads to muscle relaxation. Depolarization of the T-tubule results in release of $\mathrm{Ca}^{2+}$ from the SR, which induces muscle contraction. In skeletal muscle, there appears to be a mechanical coupling between the dihydropyridine receptor (DHPR) found in the T-tubule membrane and the CRC or ryanodine receptor (RyR) found at the terminal end of the SR (30). In cardiac muscle, $\mathrm{Ca}^{2+}$ enters the cell during the action potential through the DHPR, and initiates $\mathrm{Ca}^{2+}$ release from the SR via a mechanism known as $\mathrm{Ca}^{2+}$-induced $\mathrm{Ca}^{2+}$ release (7).
The CRC from both cardiac and skeletal muscle SR are rich in thiol groups, and are strongly regulated by thiol reagents. Oxidation of thiols results in increased $\mathrm{Ca}^{2+}$ release rates from SR vesicles, increased open probability of the reconstituted $\mathrm{CRC}$, and increased high affinity ryanodine binding to the SR, while reduction of the disulfide(s) formed results in decreased activity $(1,36,40,43)$. There are also a large number of non-thiol physiologically and pharmacologically diverse reagents known to either activate or inhibit the skeletal muscle ryanodine receptor (RyR1) and/or the cardiac muscle ryanodine receptor (RyR2). Local anesthetics such as tetracaine and procaine (42) inhibit both skeletal and cardiac muscle SR, while the polyunsaturated fatty acid docosahexaenoic acid (DHA) inhibits RyR2 (13). Caffeine activates both RyR1 and RyR2 at millimolar concentrations and

${ }^{1}$ Physics Department, Portland State University, Portland, Oregon.

${ }^{2}$ Physics Department, East China Normal University, Shanghai, China. 
sensitizes the receptor to activation at low $\mathrm{Ca}^{2+}$ concentrations (23). Both anthraquinones such as doxorubicin and mitoxanthrone, and naphthoquinones such as 1,4-naphthoquinone and menadione appear to activate the $\mathrm{Ca}^{2+}$ release mechanism of SR by oxidizing thiols on the ryanodine receptor $(1,11)$.

Previous studies have demonstrated that non-thiol regulators of L-type $\mathrm{Ca}^{2+}$ channels and $\mathrm{Na}^{+}$channels exchange electrons with dye-free radicals. Antagonists of the DHPR, such as diltiazem, verapamil, and felodipine all act as electron donors to dye-free radicals. When a dihydropyridine antagonist was chemically modified to generate an agonist, both drugs bound to the same site on the DHPR (12). However, the L-type $\mathrm{Ca}^{2+}$ channel agonist now acted as an electron acceptor (20). A correlation between electron donor/acceptor properties of a drug, as measured with dye-free radicals, and its ability to act as an inhibitor/activator of L-type $\mathrm{Ca}^{2+}$ channels suggests that modulators of the $\mathrm{Ca}^{2+}$ release mechanism might also show similar electron donor/acceptor properties.

In this paper we describe a method for measuring the redox activity of CRC regulators by their reactions with free radicals. We refer to this as a compound's weak redox activity. In spite of their diverse structures, many activators acted as electron acceptors, while many channel inhibitors acted as electron donors toward free radicals. Moreover, electron acceptors, which activate the $\mathrm{CRC}$, shift the redox potential of hyperreactive thiols to more negative values and decrease the number of reactive thiols on the RyR1, which is consistent with an oxidation of these thiols. In contrast, electron donors, which inhibit the $\mathrm{CRC}$, shift the redox potential to more positive values and increase the number of reactive thiols on RyR1, which indicates that endogenous disulfides have been reduced to thiols that are now free to react with the fluorescent maleimide CPM. These observations strongly suggest that weak redox reactions mediate the effects of nonthiol channel activators and inhibitors.

\section{MATERIALS AND METHODS}

\section{Preparation of $S R$ vesicles and RyR1s}

Skeletal muscle SR was isolated from back and leg muscles of New Zealand White rabbits by the method of MacLennan with small modifications (16). Fifty micromolar dithiothreitol and $0.2 \mu \mathrm{g} / \mathrm{ml}$ leupeptin were added to all buffers except for the final SR suspension buffer. Samples were stored in liquid $\mathrm{N}_{2}$.

Heavy SR vesicles (HSR) derived from the terminal cisternae region were purified on a discontinuous sucrose gradient as previously described (25). Approximately $6 \mathrm{mg}$ of skeletal muscle HSR was solubilized in $0.4 \%$ CHAPS and applied to a Sephacryl S300 HR gel filtration column, and fractions were eluted as previously described (38). The isolated RyR1, which was eluted in the void volume of the column, was high in ${ }^{3} \mathrm{H}-$ ryanodine binding. The protein concentration was determined using the amido black protein assay (28).

\section{$\left[{ }^{3} H\right]$-Ryanodine binding experiments}

Equilibrium binding of $\left[{ }^{3} \mathrm{H}\right]$-ryanodine was carried out according to the method of Pessah et al. (23). SR vesicles $(0.5 \mathrm{mg} / \mathrm{ml})$ were incubated with various concentrations of reagents in $0.2 \mathrm{ml}$ of standard ryanodine binding buffer containing $250 \mathrm{mM} \mathrm{KCl}, 15 \mathrm{mM} \mathrm{NaCl}, 20 \mathrm{~m} M$ Pipes, $100 \mu M$ $\mathrm{CaCl}_{2}, 50 \mu M$ EGTA, $1 \mathrm{n} M\left[{ }^{3} \mathrm{H}\right]$-ryanodine, $14 \mathrm{n} M$ ryanodine, $\mathrm{pH} 7.1$, at $37^{\circ} \mathrm{C}$ for $3 \mathrm{~h}$. Each assay was performed in duplicate and each was repeated at least three times. The binding reaction was quenched by rapid filtration through Whatman GF/B filters mounted on a 24-well Brandel Cell Harvester (Gaithersburg, MD).

The initial rate of $\left[{ }^{3} \mathrm{H}\right]$-ryanodine binding was determined from time-dependent measurements at $4,8,12$, and 16 min at $37^{\circ} \mathrm{C}$. SR vesicles $(0.5 \mathrm{mg} / \mathrm{ml})$ were incubated in $0.2 \mathrm{ml}$ of binding buffer containing $3 \mathrm{nM}\left[{ }^{3} \mathrm{H}\right]$-ryanodine. The initial binding rate was calculated from a linear regression fit of four time-dependent measurements of bound ryanodine. The derived slope is the initial rate of ryanodine binding. Subtraction of nonspecific binding does not affect the rate of binding, and therefore no subtraction was made. In redox titrations, the initial rate of ryanodine binding was measured vs. the solution redox potential, as previously described (40). The solution redox potential is defined as $\mathrm{E}_{\mathrm{sol}}=-240 \mathrm{mV}+2.3$ $(\mathrm{RT} / n \mathrm{~F}) \log _{10}[\mathrm{GSSG}] /[\mathrm{GSH}]^{2}$, where $\mathrm{R}$ is the gas constant $\left(8.31 \mathrm{deg}^{-1} \mathrm{~mol}^{-1}\right), \mathrm{T}$ is the absolute temperature $(\mathrm{K}), n$ is the number of electrons transferred $(n=2)$, and F is Faraday's constant $(96,406 \mathrm{~J} / \mathrm{V})(27)$. The binding reaction was quenched by rapid filtration through Whatman GF/B filters mounted on a 48-well Brandel Cell Harvester. Filters were rinsed three times with a wash buffer containing $50 \mu M \mathrm{Ca}^{2+}$. They were then put into scintillation vials, filled with scintillation fluid, shaken overnight, and counted the following day. All equilibrium ryanodine binding assays and measurements of the rate of ryanodine binding were repeated at least three times and are reported as the mean value \pm S.D.

\section{Measurement of redox properties of channel modulators}

Methods for determination of redox properties of biologically active compounds by their reaction with free radicals in de-aerated solutions has previously been described (19). In the presence of $\mathrm{O}_{2}$, the electron donor/acceptor activity of redox active compounds was measured as described in Fig. 1. Visible light illuminates a dye (methylene blue)-containing solution, which leads to the production of dye anion (Dye ${ }^{\bullet-}$ ) and dye cation $\left(\mathrm{Dye}^{\bullet+}\right.$ ) radicals. Under normal conditions, the dye anion and cation radicals rapidly recombine. However, in the presence of an electron donor, its electrons are passed to the dye cation radicals, decreasing their concentration, and increasing the lifetime of the dye anion radical. When two anion radicals combine, the dye bleaches. In the presence of $\mathrm{O}_{2}$, the dye anion radicals and the bleached dye reduce $\mathrm{O}_{2}$ to form superoxide $\left(\mathrm{O}_{2}^{\bullet-}\right)$. The superoxide produced is detected with an optical probe such as NBD-Cl (4-chloro-7-nitrobenzo-2-oxa-1, 3-diazole) (22) or XTT (2,3-bis(2-methoxy-4-nitro-5-sulfophenyl)-2H-tetrazolium-5carboxanilide) (33). The spectral changes were quantified by measuring the increased absorbance at $470 \mathrm{~nm}$ as a function of time using a HP8452A diode array spectrophotometer (Hewlett-Packard/Agilent Technology, Santa Clara, CA) or an Ocean Optics (Dunedin, FL) USB2000 UV/Visible spectrophotometer. 


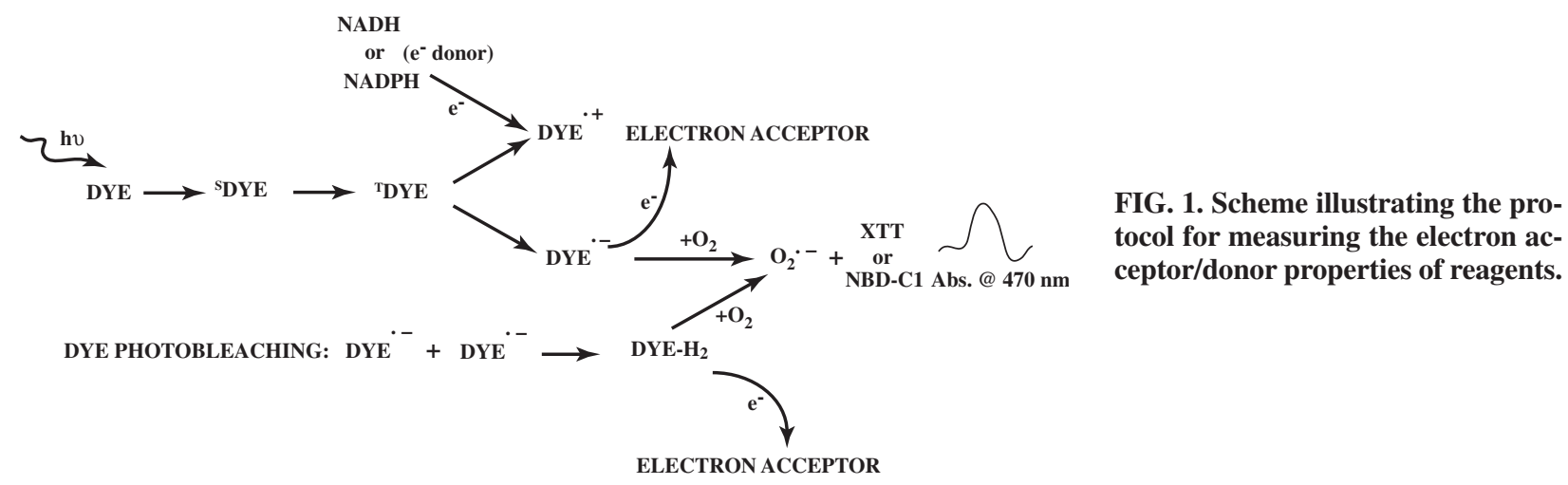

In the presence of a drug that accepts electrons from dye anion radicals, dye photo bleaching decreases and the production of superoxide also decreases. For better sensitivity, the initial concentration of dye anion radicals was increased in the presence of an auxiliary electron donor such as NADH or EDTA. The difference between the probe's absorbance at $470 \mathrm{~nm}$ as well as the bleaching of the dye in the presence and absence of the compound are taken as a measure of electron-acceptor activity of the compound.

In order to test whether a compound is an electron donor, the auxiliary donor was replaced with the reagent to be tested. If the compound tested is an electron donor, dye photo bleaching increases, as does the production of superoxide, which is detected with NBD-Cl or XTT.

These assays monitor the ability of drugs to donate electrons to dye cation radicals, or to accept electrons from dye anion radicals. The redox potential of dye cation radicals are very positive, while the redox potential of the dye anion radicals are very negative. The cation radicals readily accept electrons from a "weak electron donor," while the anion radicals readily donates electrons to a "weak electron acceptor." This represents a sensitive assay to measure the "weak redox" properties of drugs.

All measurements of the electron donor/acceptor properties of different modulators of the $\mathrm{CRC}$ were repeated at least three times. The mean \pm the standard deviations are shown in Figs. 2-5.

\section{Kinetics of CPM labeling}

SR was labeled with 7-diethylamino-3-(4'-maleimidylphenyl)-4-methylcoumarin (CPM) using the method of Liu et al. (15), as modified by Xia et al. (40). SR at $0.1 \mathrm{mg} / \mathrm{ml}$ was incubated in standard ryanodine binding buffer (without ryanodine) containing $20 \mu M \mathrm{Ca}^{2+}$ with various concentrations of caffeine, and/or tetracaine at room temperature with rigorous stirring. The reaction was initiated by addition of $80 \mathrm{n} M \mathrm{CPM}$, and its fluorescence $\left(\lambda_{\text {excitation }}=397 \mathrm{~nm}, \lambda_{\text {emission }}\right.$ $=465 \mathrm{~nm}$ ) was monitored over a 3-min time scale using a PTI (Birmingham, NJ) QuantaMaster Model QM-4/2005 spectrofluorometer. Control experiments showed that neither tetracaine nor caffeine change the fluorescence of CPM, subsequent to its reaction with SR thiols.

\section{Measurement of thiol content of RyRI}

The isolated RyR1 $(1.0 \mu \mathrm{g} / \mathrm{ml})$ was suspended in a buffer containing $250 \mathrm{mM} \mathrm{KCl}, 15 \mathrm{~m} M \mathrm{NaCl}, 20 \mathrm{~m} M$ Pipes, $\mathrm{pH}$ 7.1, with different concentrations of CRC modulators for $10 \mathrm{~min}$ at room temperature. The thiol-specific fluorescent probe CPM $(10 \mu M)$ was added and incubated with the RyR1 for $30 \mathrm{~min}$. The final CPM fluorescence was measured at an excitation wavelength of $397 \mathrm{~nm}$ and an emission wavelength of $465 \mathrm{~nm}$. Calibrations of the CPM fluorescence vs. [GSH] were linear over the range of $0-5 \mu M$ GSH. The calculated number of thiols is normalized to the number of moles of RyR1. Measurements were repeated four times, with the mean \pm SD shown.

\section{Chemicals}

Ryanodine was purchased from Calbiochem (San Diego, CA). $\left[{ }^{3} \mathrm{H}\right]$-ryanodine was purchased from Perkin Elmer Life Sciences (Boston, MA). Hepes and Pipes were purchase from Research Organics (Cincinnati, OH). Mitoxantrone diacetate was a gift from the Drug Synthesis and Chemistry Branch, Division of Cancer Treatment, National Cancer Institute. CPM was purchased from Invitrogen Molecular Probes (Eugene, OR). All other reagents were purchased from Sigma-Aldrich (St. Louis, MO).

\section{RESULTS}

Caffeine activates the $\mathrm{SR} \mathrm{Ca}^{2+}$ release mechanism and increases ryanodine binding at millimolar concentrations (23). As shown in Fig. 2, caffeine acts as an electron acceptor at low millimolar concentrations. Illumination of a methylene blue (MB) solution with NADH results in fast MB bleaching and superoxide production in the control sample (without caffeine). Caffeine dose-dependently decreased both dye photo bleaching and superoxide production, manifesting its electron acceptor properties. In the absence of light, no MB bleaching is observed.

Anthraquinones, such as doxorubicin and mitoxanthrone, are widely used antineoplastic agents. However, their usefulness as anti-tumor agents is limited by their cardiotoxicity. Previous studies have shown that both doxorubicin and mitoxanthrone are potent stimulators of the CRC, and that $\mathrm{Ca}^{2+}$ release induced by these agents is reversed by subsequent addition of the reducing agent dithiothreitol (1). This suggests that both of these reagents induce $\mathrm{Ca}^{2+}$ release by promoting the oxidized state of thiols associated with the 


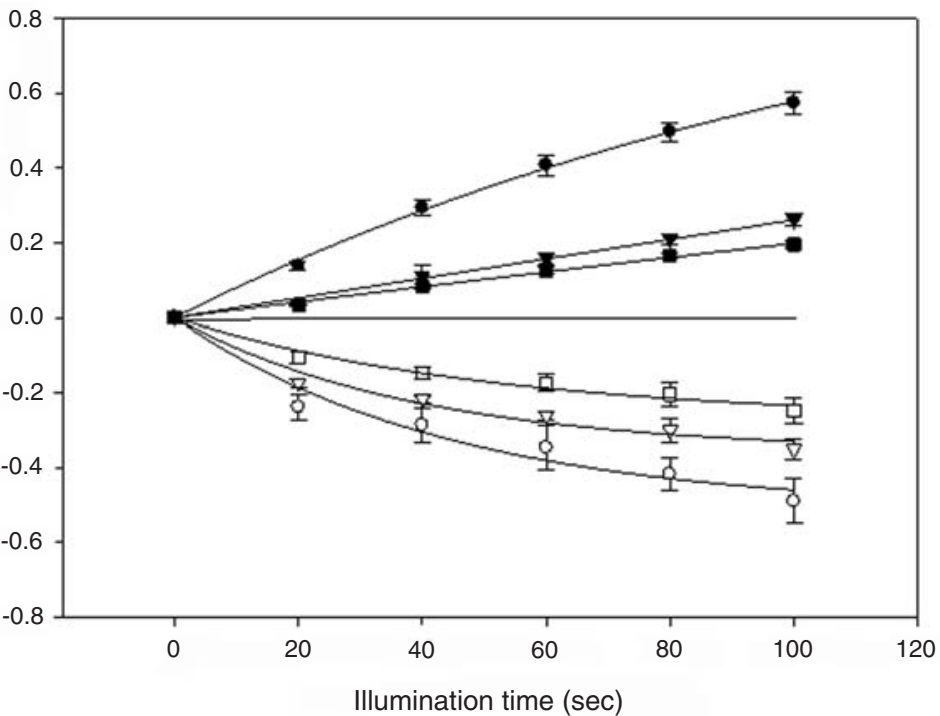

FIG. 2. Caffeine is an electron acceptor. A mixture of $80 \%$ DMSO and $20 \%$ buffer (10 mM Tris, pH 7.4), containing $200 \mu M$ EDTA (as an electron donor), $10 \mu M$ methylene blue, $100 \mu M$ NBD-Cl. Photo bleaching of methylene blue was followed as a decrease in the absorption at $663 \mathrm{~nm}$ (open symbols), and the reduction of NBD-Cl was simultaneously recorded as an increase in the absorbance at $470 \mathrm{~nm}$ (filled symbols) as a function of time of illumination using a projector $\left(3.0 \mathrm{~mW} / \mathrm{cm}^{2}\right)$ with light passing through a band pass filter $(600-700 \mathrm{~nm})$ in an aerobic environment. Control traces $(\mathrm{O}, \bullet)$, with $1.0 \mathrm{~m} M$ caffeine $(\nabla, \boldsymbol{\nabla})$, and $2.0 \mathrm{~m} M$ caffeine $(\square, \square)$ are superimposed. The solid lines shown are time-dependent exponential fits to the data. The data shown are the mean \pm S.D. $(n=3)$.
CRC. This hypothesis is supported by the data presented in Fig. 3. Doxorubicin $(40 \mu M)$ and mitoxanthrone $(10 \mu M)$ decrease the bleaching of $\mathrm{MB}$, and simultaneously decrease NBD-Cl reduction by superoxide. Both of these anthraquinones act as electron acceptors.

In vivo, the cytoplasm of the cell is maintained in a reducing environment by a large excess of reduced glutathione (GSH) over oxidized glutathione (GSSG). A previous study has shown that GSSG increases ryanodine binding and activates the $\mathrm{CRC}$, while GSH decreases ryanodine binding and inactivates the CRC (43). Figure 4A shows that superoxide production $\left(\mathrm{A}_{470}\right)$ and dye bleaching $\left(\mathrm{A}_{663}\right)$ promoted by the auxiliary electron donor NADH in the control samples are at- tenuated by the thiol oxidizing agents cystine, GSSG, and diamide. It is likely that all of these agents act as electron acceptors, accepting electrons from MB anion radicals, and hence decreasing dye photo bleaching and the production of superoxide. At equal concentrations $(1 \mathrm{~m} M)$, cystine was a more potent electron acceptor than GSSG, while diamide showed comparable electron acceptor activity with cystine at a much lower concentration. Measurements of the electron donor properties of cysteine and GSH (Fig. 4B) were carried out in the absence of the auxiliary electron donor NADH. Photo bleaching of methylene blue is more rapid and complete in the presence of cysteine than it is with equal concentration of GSH. Cysteine is a better electron donor than is

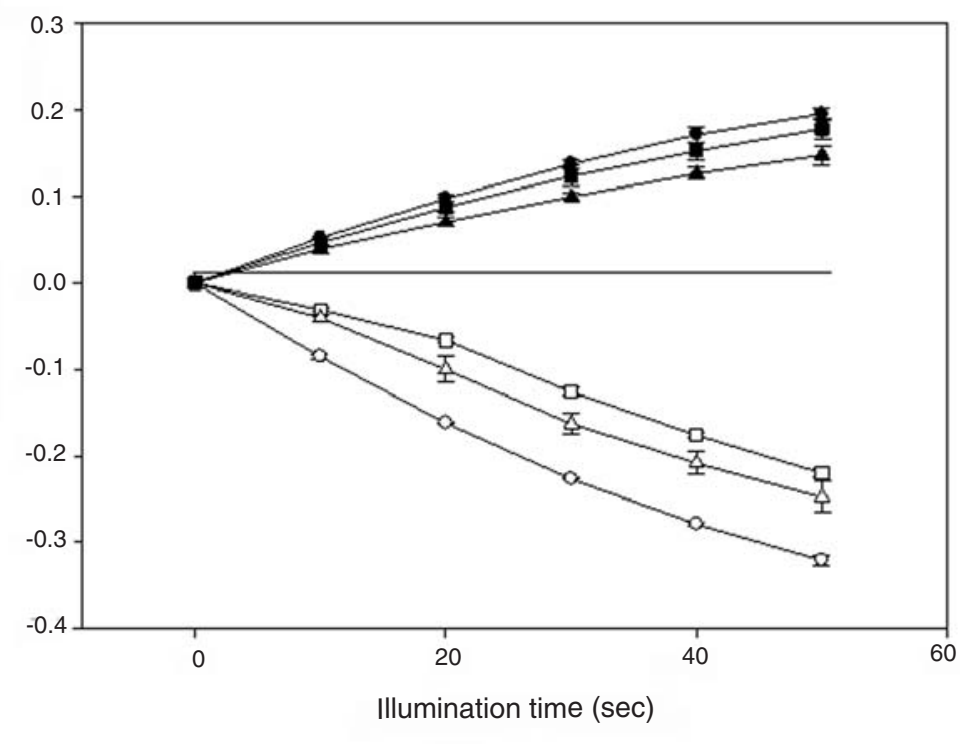

FIG. 3. Electron acceptor activity of the anthraquinones doxorubicin and mitoxanthrone. Samples were continuously illuminated, as described in Fig. 2, in a buffer containing $1.0 \mathrm{~m} M$ Tris, $\mathrm{pH}$ 7.3, $50 \mu M$ NADH, $10 \mu M$ methylene blue, $100 \mu M$ NBD-Cl. Photo bleaching of methylene blue (open symbols), and reduction of NBD-Cl (filled symbols) are shown as a function of illumination time. Control traces $(\bigcirc, \bullet)$, with $40 \mu M$ doxorubicin $(\square, \square)$, or $10 \mu M$ mitoxanthrone $(\triangle, \boldsymbol{\Lambda})$. The data shown are the mean \pm S.D. $(n=3)$. 

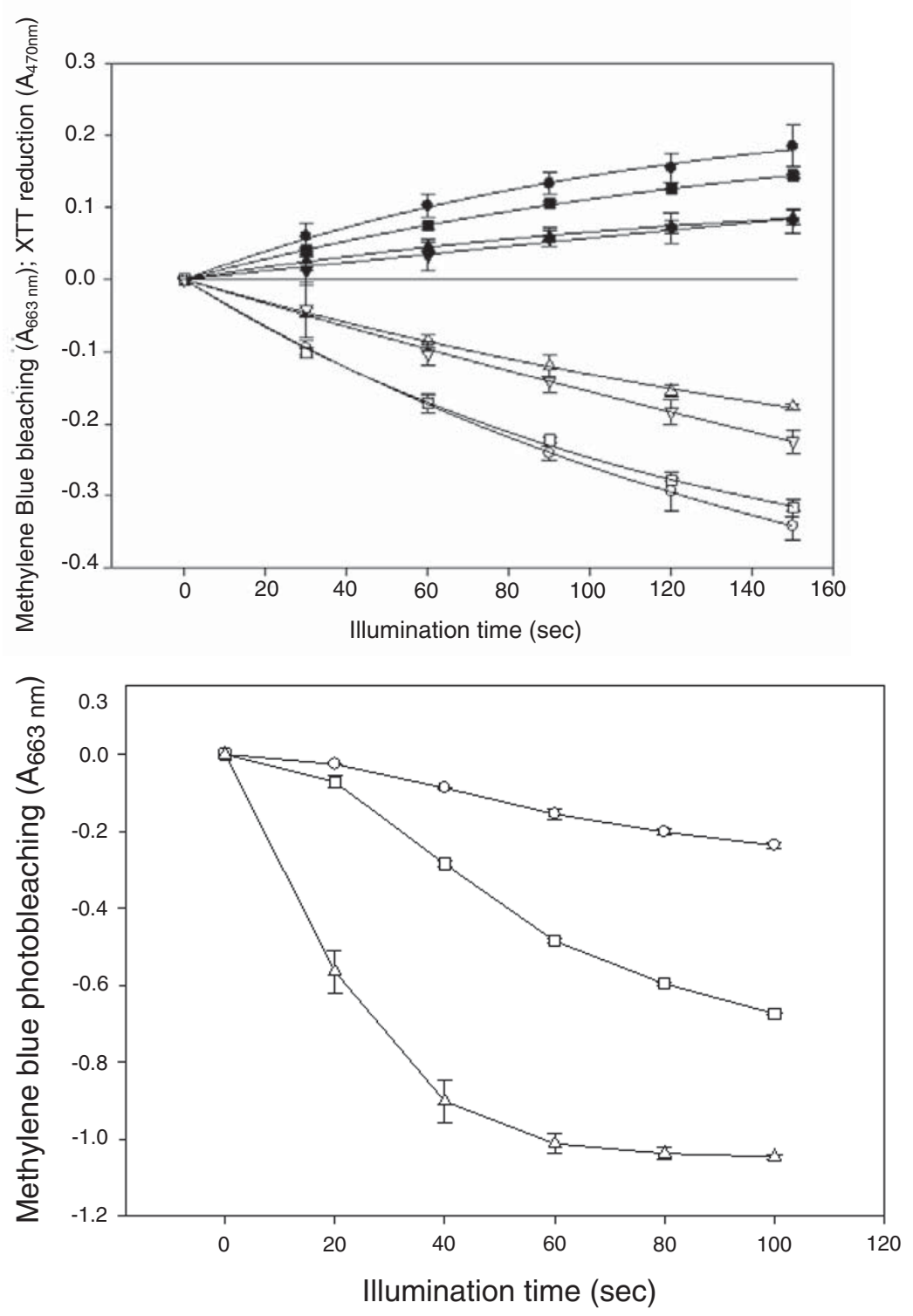

FIG. 4. Thiol oxidizing agents are electron acceptors and thiol reducing agents are donors of electrons. (A) Samples were continuously illuminated, as described in Fig. 2, in a buffer containing $1.0 \mathrm{~m} M$ Tris, $\mathrm{pH} 7.3,50 \mu M$ NADH, $10 \mu M$ methylene blue, $100 \mu M$ XTT. Photo bleaching of methylene blue (open symbols), and reduction of XTT (filled symbols) are shown as a function of illumination time. Control traces $(\bigcirc, \bullet)$, with $1.0 \mathrm{~m} M \operatorname{GSSG}(\square, \mathbf{\square})$, $1.0 \mathrm{~m} M$ cystine $(\triangle, \boldsymbol{\Delta})$, or $50 \mu M$ diamide $(\nabla, \boldsymbol{\nabla})$. (B) Samples were illuminated in a mixture of $80 \%$ DMSO and $20 \%$ buffer (1.0 $\mathrm{m} M$ Tris, $\mathrm{pH} 7.3$ ), containing $10 \mu M$ methylene blue. Control traces (O), with $1.0 \mathrm{mM}$ GSH ( $\square)$, or $1.0 \mathrm{~m} M$ cysteine $(\triangle)$. The data shown are the mean \pm S.D. $(n=3)$.
GSH, in spite of the fact that they have similar redox potentials. In the dark, both cysteine and GSH are able to reduce NBD-Cl and XTT but not MB. Therefore, measurements in Fig. 4B were carried out in the absence of either XTT or NBD-Cl.

Some CRC inhibitors are compounds that block voltagedependent $\mathrm{Na}^{+}$channels, like local anesthetics. It has previously been shown that local anesthetics reversibly inhibit single channel activity of the isolated RyR1, and $\mathrm{Ca}^{2+}$ fluxes across SR vesicles (42). Inhibition of CRC activity induced by tetracaine is not voltage dependent. Unlike GSH and cysteine, the local anesthetics tetracaine and procaine do not contain sulfhydryl groups. In the control, slow MB bleaching was caused by a low concentration of Tris $(200 \mu M)$ with marginal donor activity. Tetracaine and procaine $(50 \mu M)$ both increased dye photo bleaching, manifesting their electron donor activity. However, tetracaine was a better electron donor than procaine (Fig. 5). A Na+ channel blocker with a different structure, the polyunsaturated fatty acid DHA, also behaved as an electron donor promoting dye bleaching but at a higher concentration $(400 \mu M)$. Tetracaine and procaine do not bleach methylene blue in the absence of light.

Polyunsaturated fatty acids appear to protect myocytes from the consequences of ischemia. It has been shown that docosahexaenoic acid (DHA) reduced the intensity of $\mathrm{Ca}^{2+}$ sparks in single rat myocytes and inhibits single channel activity of the cardiac CRC at micromolar concentrations (13). In Fig. 5, it is shown that, in a similar concentration range, DHA increases the rate and amount of methylene blue photo bleaching. DHA acts as an electron donor and inhibits ryanodine binding to SR (Fig. 6). The $\mathrm{IC}_{50}$ for DHA inhibition of the skeletal muscle ryanodine receptor was $\sim 100 \mu M$, which was approximately twice as high as the corresponding value reported with the cardiac receptor (13). No significant 


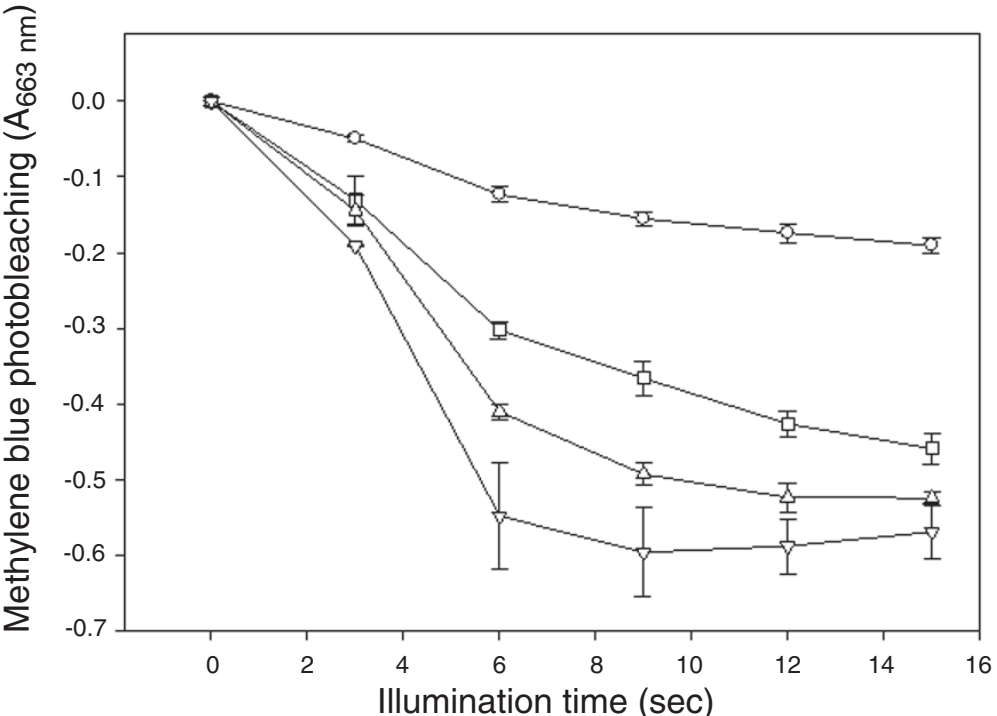

FIG. 5. Local anesthetics and docosahexaenoic acid are electron donors. Samples were illuminated in a mixture of $80 \%$ DMSO and $20 \%$ buffer (1.0 $\mathrm{m} M$ Tris, $\mathrm{pH} 7.3$ ), containing $10 \mu M$ methylene blue and $100 \mu M$ NBDCl. Control traces (O), with $400 \mu M$ DHA ( $\square)$, $50 \mu M$ procaine $(\triangle)$, or $50 \mu M$ tetracaine $(\nabla)$. The data shown are the mean \pm S.D. $(n=3)$. electron acceptor properties were observed for the channel inhibitors tested (data not shown).

Caffeine is one of the earliest known activators of $\mathrm{Ca}^{2+}$ release from SR (38). At millimolar concentrations, caffeine activates ryanodine receptor binding (23), and single channel activity (24). Figure 2 shows that caffeine acts as an electron acceptor, while in Fig. 5 it is shown that the local anesthetics tetracaine and procaine, which inhibit the CRC, are electron donors. If there is a common site or sites in which electrons are exchanged within the RyR1, when these reagents modify channel function, then one might expect that caffeine and tetracaine should competitively interact with one another. In Fig. 7A, we examine the ability of caffeine to activate the ini- tial rate of ryanodine binding in the absence and presence of $15 \mu M$ and $50 \mu M$ tetracaine. The data were fit to the Michaelis-Menton equation. As seen in Fig. 7A, in the presence of increasing concentrations of tetracaine, higher concentrations of caffeine are required to obtain the same initial rate of ryanodine binding. Tetracaine antagonizes caffeine's activating effects. In Fig. 7B, the data derived from Fig. 7A are replotted as a double reciprocal plot. $v_{0}$ represents the rate of ryanodine binding in the absence of caffeine, $\left(v-v_{\mathrm{o}}\right)$ denotes the amount of activation of the rate of ryanodine binding induced by caffeine. The fit lines intersect the ordinate at a single point, indicating that tetracaine and caffeine competitively interact in modulating the function of the

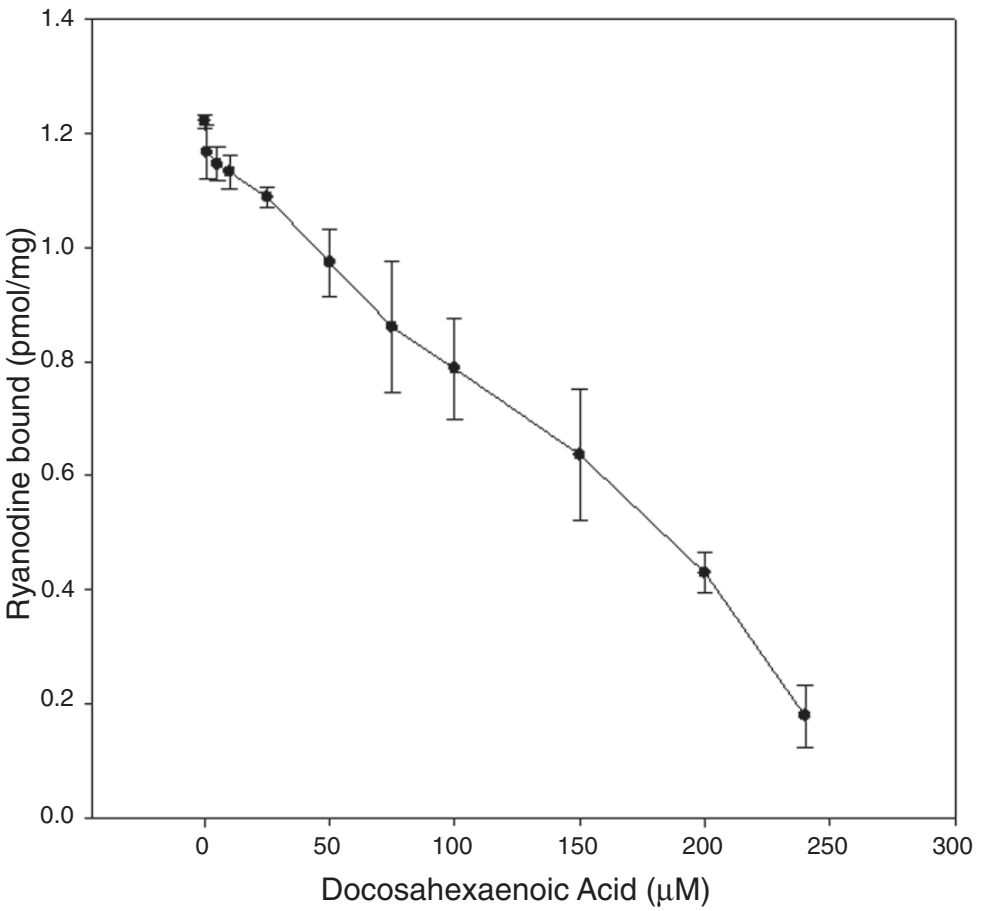

FIG. 6. Docosahexaenoic acid inhibits ryanodine binding to SR. Equilibrium $\left[{ }^{3} \mathrm{H}\right]$-ryanodine binding was measured as described in $\mathrm{Ma}$ terials and Methods. SR vesicles $(0.5 \mathrm{mg} / \mathrm{ml})$ were incubated in buffer containing $250 \mathrm{mM}$ $\mathrm{KCl}, 15 \mathrm{~m} M \mathrm{NaCl}, 20 \mathrm{~m} M$ Pipes, $100 \mu \mathrm{M} \mathrm{CaCl}_{2}$, $50 \mu M$ EGTA, $1 \mathrm{n} M\left[{ }^{3} \mathrm{H}\right]$-ryanodine, $14 \mathrm{n} M$ ryanodine, $\mathrm{pH} 7.1$, as a function of [DHA] at $37^{\circ} \mathrm{C}$ for $3 \mathrm{~h}$. Each assay was performed in duplicate and each was repeated three times. The data shown are the mean \pm S.D. $(n=3)$. 

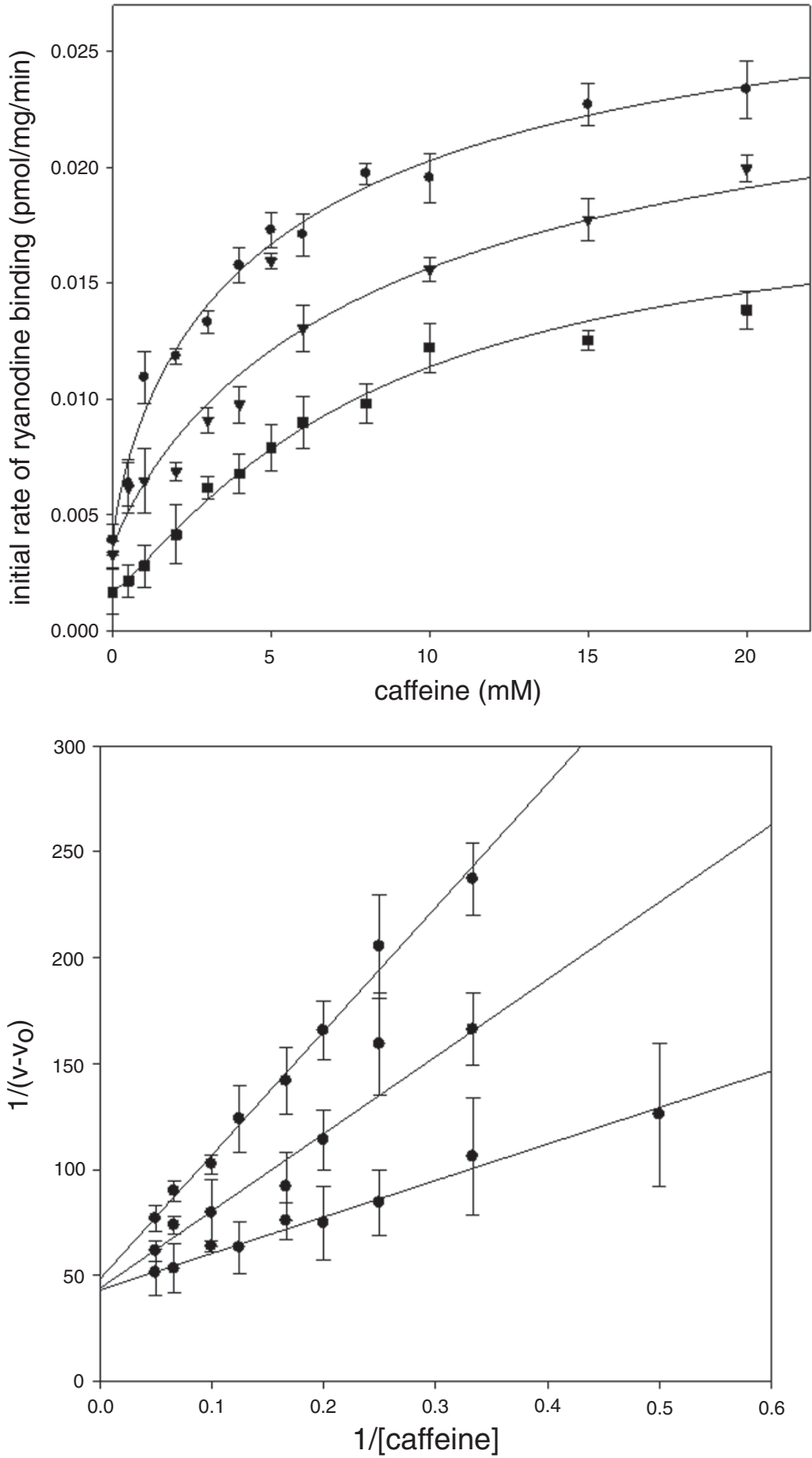

FIG. 7. Tetracaine competitively inhibits caffeine activation of ryanodine binding. The initial rate of ryanodine binding was measured as in Materials and Methods. (A) The initial rate of ryanodine binding is plotted versus the caffeine concentration in the absence (๑) or presence of $15 \mu M$ tetracaine $(\boldsymbol{\nabla})$ or $50 \mu M$ tetracaine $(\boldsymbol{\square})$. (B) The same data is displayed in a double reciprocal plot. $v$ the initial rate of ryanodine binding in the absence of caffeine; $v$, the initial rate of ryanodine binding in the presence of the indicated concentration of caffeine. All measurements were made at $37^{\circ} \mathrm{C}$. The data shown are the mean \pm S.D. $(n=3)$.
RyR1. In a similar manner, doxorubicin, an activator of RyR1(1), and an electron acceptor (Fig. 3) also competitively interacts with tetracaine (not shown). Although the structures of doxorubicin and caffeine are very different from that of the local anesthetic tetracaine, and it is unlikely that they bind to the same site on the RyR, they competitively interact. The electron donor, tetracaine, and the electron acceptors, caffeine and doxorubicin, appear to functionally compete by donating electrons to or accepting electrons from a common site or sites.
Using the maleimide CPM, which fluoresces when it reacts with thiols, it has been demonstrated that there exists a class of hyperreactive thiols on RyR1 which are exposed when the $\mathrm{Ca}^{2+}$ release channel is in the closed configuration (15). The rate of CPM fluorescence increases $\sim 10$-fold in the closed configuration of the CRC. Seven thiols per monomeric receptor unit have recently been identified as hyperreactive (37), one of which (cys 3635) had previously been identified as the binding site for NO and calmodulin (32). It has previously been shown that these hyperreactive thiols have a 


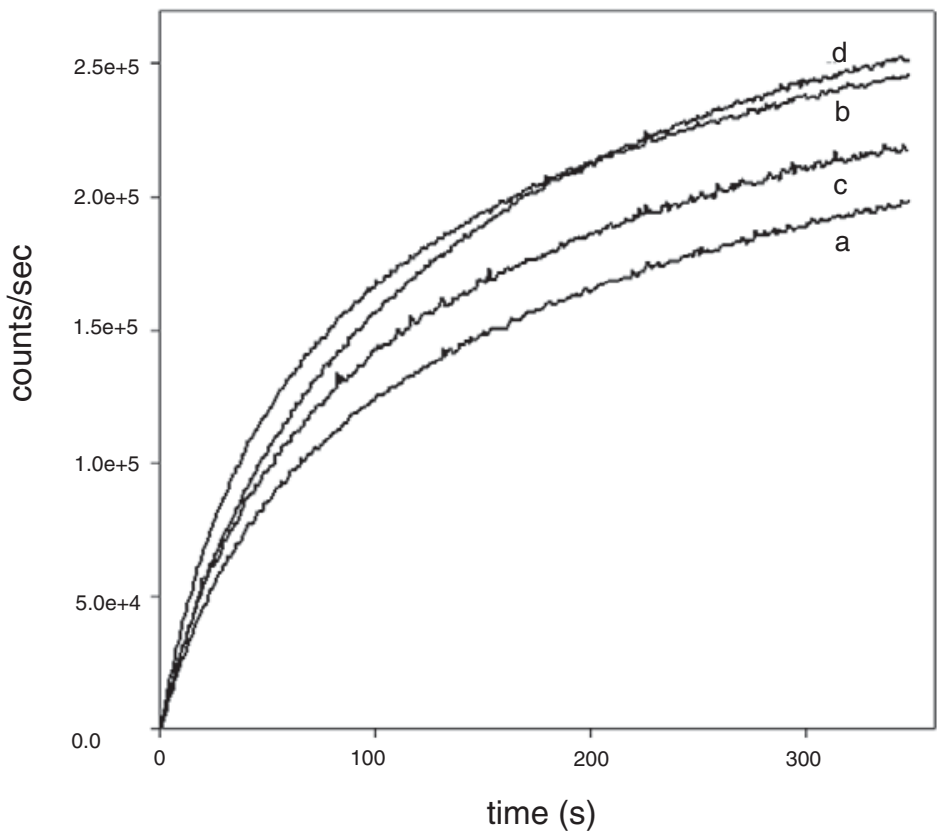

FIG. 8. Caffeine and tetracaine modify reactivity of hyperreactive thiols oppositely. SR vesicles $(0.1 \mathrm{mg} / \mathrm{ml})$ were treated with increasing concentrations of caffeine and tetracaine in standard ryanodine binding buffer containing: (a) $50 \mu M \mathrm{Ca}^{2+}$; (b) $20 \mu M \mathrm{Ca}^{2+}$ (40 $\mu M \mathrm{Ca}^{2+}+20 \mu M$ EGTA); (c) $20 \mu M \mathrm{Ca}^{2+}$ free $+2 \mathrm{mM}$ caffeine; (d) $20 \mu M \mathrm{Ca}^{2+}$ $+2 \mathrm{~m} M$ caffeine $+5 \mu M$ tetracaine. The reaction was initiated by the addition of $80 \mathrm{n} M$ CPM. CPM fluorescence (excitation at $397 \mathrm{~nm}$, emission at 465 $\mathrm{nm}$ ) is expressed in counts per second (cps). This experiment was repeated three times with very similar results. well-defined redox potential which is sensitive to the open versus closed state of the CRC (40).

Not only do caffeine and tetracaine competitively interact to activate and inhibit the rate of ryanodine binding (Fig. 7), the development of CPM fluorescence is also oppositely affected by caffeine and tetracaine (Fig. 8). In the presence of a $\left[\mathrm{Ca}^{2+}\right]$ optimal for channel activity $(50 \mu M)$, the rate of CPM fluorescence is relatively slow (control; trace $a$ ). The rate of $\mathrm{CPM}$ fluorescence is increased at a lower $\left[\mathrm{Ca}^{2+}\right](20 \mu \mathrm{M}$; trace $b$ ). Caffeine ( $2 \mathrm{mM}$; trace $c$ ) slows down the kinetics of CPM fluorescence. In the presence of $20 \mu M \mathrm{Ca}^{2+}+2 \mathrm{mM}$ caffeine, addition of $5 \mu M$ tetracaine (trace $d$ ), reverses the effect of caffeine, and increases the rate of alkylation of hyperreactive thiols by CPM. The effects of the CRC activators $\mathrm{Ca}^{2+}$ and caffeine, and the inhibitor tetracaine oppositely affect the thiol status within the CRC.

This observation is supported by the effects of channel regulators on the redox potential of hyperreactive thiols on the CRC. Redox titrations, using GSH and GSSG to set the solution redox potential, have been used to measure the redox potential of hyperreactive thiols associated with the CRC (40). As the redox potential becomes more positive (more oxidizing), the rate of ryanodine binding increases. As the potential becomes more negative (more reducing), the rate of ryanodine binding decreases to a minimum value $\left(d B / d t_{\min }=0.002\right.$ $\mathrm{pmol} / \mathrm{mg} / \mathrm{min}$ ). The redox potential of the receptor corresponds to the point at which half of the reactive thiols are oxidized and half are reduced. This corresponds to the point at which the initial rate of ryanodine binding is half maximal. Figure 9A shows the rate of ryanodine binding to an SR vesicle suspension. In the control titration $\left(20 \mu M \mathrm{Ca}^{2+}\right)$, reactive thiols have a redox potential of $-160.3 \pm 3.2 \mathrm{mV}$. Caffeine $(2 \mathrm{mM}$ ) shifts the curve to the left, causing the redox potential to become more negative $(-197.8 \pm 5.8 \mathrm{mV})$. In contrast, in the presence of a CRC inhibitor, $25 \mu M$ tetracaine, the redox potential shifts to a more positive value $(-147.7 \pm 2.8 \mathrm{mV})$.
Tetracaine has shifted the redox balance of SR thiols to a more reduced state. As observed in Fig. 8, in the presence of $2 \mathrm{mM}$ caffeine $+5 \mu M$ tetracaine, CPM binding to hyperreactive thiols is similar to control kinetics (compare Fig. 8, traces $b$ and $d$ ). In a similar manner, the redox titration in the presence of $2 \mathrm{~m} M$ caffeine $(-197.8 \pm 5.8 \mathrm{mV})$ shifts toward the control value $(-160.3 \pm 3.2 \mathrm{mV})$ in the presence of $2 \mathrm{mM}$ caffeine + $5 \mu M$ tetracaine $(-171.3 \pm 2.1 \mathrm{mV}$ ). The effect of caffeine (an electron acceptor) is to shift the redox state of hyperreactive thiols to a more oxidized state, while the effect of tetracaine (an electron donor) is to shift these thiols to a more reduced state.

The ability of caffeine to shift the thiol/disulfide balance toward a more oxidized state, and the ability of tetracaine to shift reactive thiols toward a more reduced state is also demonstrated by measuring the number of free thiols in the isolated RyR1 (Fig. 9B). For this purpose, a large excess of CPM was incubated with the isolated RyR for 30 min to ensure that all accessible SH groups on the RyR had reacted with CPM. The number of accessible thiols in the absence of added channel modulators $(46.9 \pm 1.8$ /mole of RyR 1$)$ was observed with three different preparations of the isolated RyR1. Caffeine decreased dose-dependently the number of CPM labeled thiols to $35.1 \pm 5.1 /$ mole of RyR 1 at $3 \mathrm{mM}$ (filled circles in Fig. 9B). This corresponds to a loss of $11.8 \pm 5.4$ thiols $/$ mole of RyR1. In the presence of tetracaine, the number of CPM-labeled thiols increase up to $66.9 \pm 3.1 /$ mole of RyR 1 at $3 \mathrm{mM}$ tetracaine (open circles). This corresponds to an increase of $20.0 \pm 3.6$ thiols/mole of RyR 1 . The skeletal muscle ryanodine receptor contains 100 cysteines/RyR1 (34) plus 1 cysteine per FK506 binding protein (14). The fractional change in the number of reactive thiols upon addition of caffeine and tetracaine corresponds to $11.8 \%$ and $20 \%$. respectively. Treatment of the isolated RyR 1 with $2 \mathrm{mM}$ caffeine $+25 \mu M$ or $50 \mu M$ tetracaine restores the number of CPM accessible thiols/mole of RyR 1 to $46.5 \pm 1.8$, and $48.7 \pm 2.1$, respectively (triangles). 

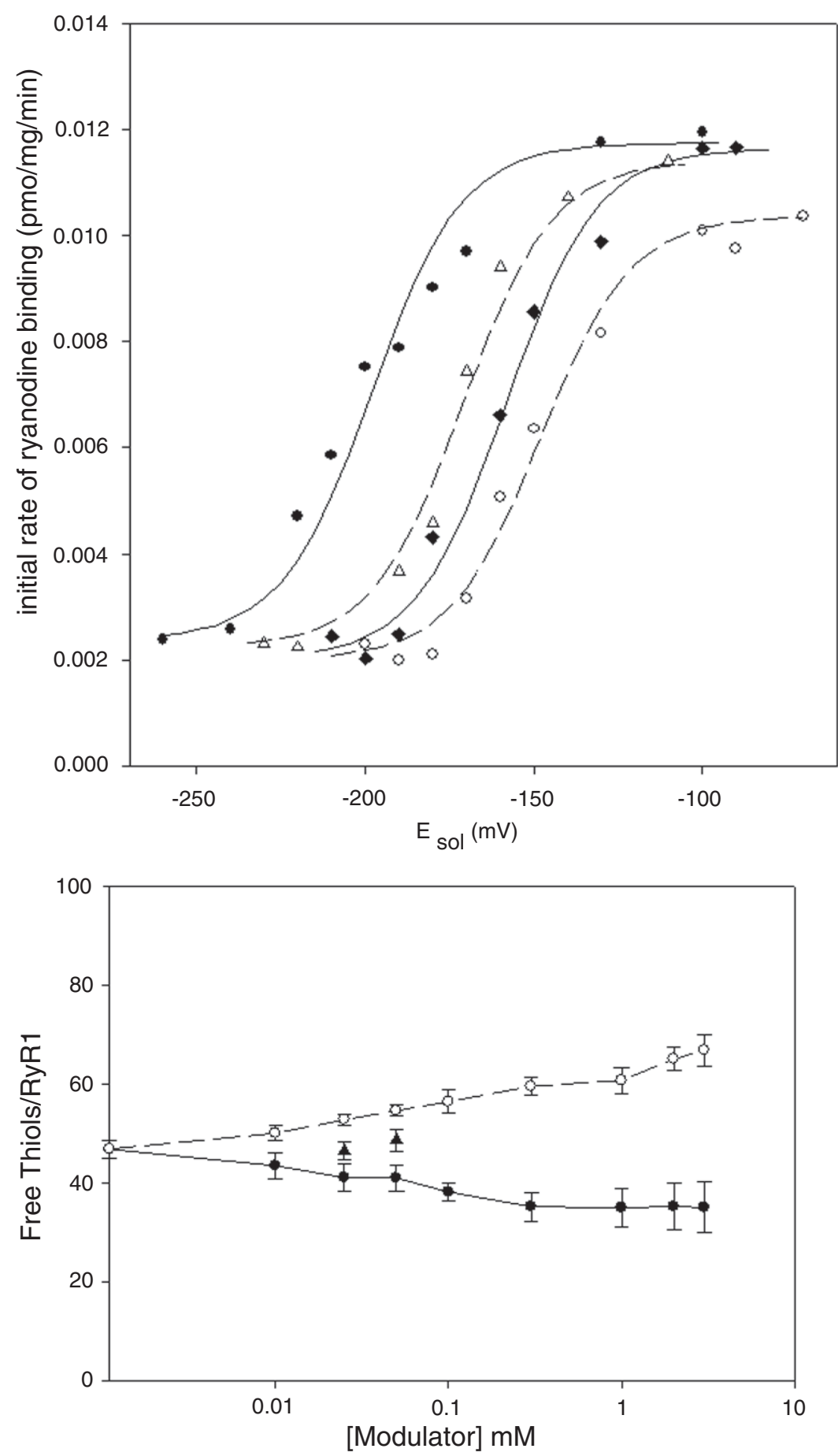

FIG. 9. Caffeine and tetracaine alter the redox potential and the number of reactive thiols on the RyR1. (A) The initial rate of ryanodine binding was measured as a function of solution redox potential, as described in Materials and Methods over a $16 \mathrm{~min}$ time period. The control experiment was carried out with $20 \mu M$ $\mathrm{Ca}^{2+}\left[\mathrm{E}_{\mathrm{RyR}}=-160.3 \pm 3.2 \mathrm{mV}\right](\diamond)$, or with $20 \mu M \mathrm{Ca}^{2+}+2 \mathrm{~m} M$ caffeine $\left[\mathrm{E}_{\mathrm{RyR}}=\right.$ $-197.8 \pm 5.8 \mathrm{mV}](\bullet)$, with $20 \mu M \mathrm{Ca}^{2+}+$ $25 \mu M$ tetracaine $\left[\mathrm{E}_{\mathrm{RvR}}=-147.7 \pm 2.8\right.$ $\mathrm{mV}](\mathrm{O})$, or with $20 \mu M \mathrm{Ca}^{2+}+2 \mathrm{mM}$ caffeine $+5 \mu M$ tetracaine $\left[\mathrm{E}_{\mathrm{RyR}}=-171.3 \pm\right.$ $2.1 \mathrm{mV}](\triangle)$. All assays were carried out at $37^{\circ} \mathrm{C}$, in ryanodine binding buffer containing $3 \mathrm{n} M^{3} \mathrm{H}$-ryanodine at an SR concentration of $0.1 \mathrm{mg} / \mathrm{ml}$. The redox potential $\left[E_{\mathrm{RyR}}=\right.$ mean \pm S.D. $]$ was derived from at least three experiments. (B) Following exposure of the isolated RyR1 $(1.0 \mu \mathrm{g} / \mathrm{ml})$ in a buffer containing $250 \mathrm{mM} \mathrm{KCl}, 15 \mathrm{mM}$ $\mathrm{NaCl}, 20 \mathrm{~m} M$ Pipes, $\mathrm{pH} 7.0$, to increasing concentrations of caffeine $(\bullet)$, or tetracaine $(\bigcirc)$, or caffeine + tetracaine $(\boldsymbol{\Lambda})$ for $10 \mathrm{~min}$ at room temperature, samples were exposed to $10 \mu M \mathrm{CPM}$ for $30 \mathrm{~min}$, and the fluorescence was measured (excitation at $397 \mathrm{~nm}$, emission at $465 \mathrm{~nm}$ ). CPM fluorescence was calibrated with known concentrations of GSH $(0-5 \mu M)$ and the signal was normalized to the [RyR] derived from the amido black assay (28). The data shown are the mean \pm S.D. $(n=4)$.

\section{DISCUSSION}

The main finding in this work is the discovery of the weak redox properties of regulators of the calcium release channel from SR. Channel activators were shown to be electron acceptors while channel inhibitors were shown to be electron donors. The weak redox properties of these CRC regulators appear to control the reactivity of critical thiols, their redox potential, and the thiol/disulfide balance within the ryanodine receptor protein. These observations suggest that the weak redox activity of $\mathrm{CRC}$ modulators underlie the molecular mechanisms of their action.

The $\mathrm{SR} \mathrm{Ca}^{2+}$ release mechanism has previously been shown to be sensitive to thiol oxidizing and reducing agents. Addition of physiologically relevant thiol oxidizing agents $\left(\mathrm{H}_{2} \mathrm{O}_{2}, \mathrm{HOCl}, \mathrm{GSSG}\right.$ and superoxide) activate the CRC $(8-10,41)$, while addition of thiol reducing agents (GSH, DTT, and $\beta$-mercaptoethanol) inhibit the CRC (43). The list of pharmacologically interesting thiol oxidizing agents that increase the activity of the CRC is large $(2,21,36)$. Moreover, 
the activation of the RyR by NO, $S$-nitrosocysteine, and HNO all are due to their interaction with endogenous thiols associated with the RyR $(4,6,31)$.

It has been shown that the $\mathrm{SR} \mathrm{Ca}^{2+}$ release mechanism contains hyperreactive thiols that are readily labeled with the fluorescent maleimide CPM when the channel is in a closed state, but are not accessible when channel activators are added (15). Moreover, these thiols have a well-defined redox potential which is sensitive to the open versus closed state of the CRC (40). Addition of a non-thiol $\mathrm{Ca}^{2+}$ release channel activator shifts the redox potential of these thiols to more negative values, which favors the oxidation of these thiols, and significantly decreases the number of CPM accessible thiols. In contrast, addition of a non-thiol channel inhibitor, shifts the redox potential of these thiols to more positive values, which favors the reduced state of these thiols, and significantly increases the number of CPM reactive thiols (Fig. 9). The effects of these non-thiol activators and inhibitors are reversible. It has been proposed that during oxidative stress, when the cellular redox potential becomes more positive, these thiols oxidize, and as a result the cellular $\mathrm{Ca}^{2+}$ concentration increases (40). The reason for the shift in the redox potential of hyperreactive thiols induced by addition of channel activators or inhibitors was believed to be driven by the conformational state of the RyR. In this paper an alternative model is presented.

Using a model system for assaying the electron donor versus electron acceptor properties of $\mathrm{Ca}^{2+}$ channel modulators, we observe for the first time that many $\mathrm{Ca}^{2+}$ channel activators were weak electron acceptors, and that many $\mathrm{Ca}^{2+}$ channel inhibitors tested were weak electron donors. The donation of electrons favors the reduced state of endogenous protein thiols. The withdrawal of electrons by the addition of an electron acceptor favors the oxidized state of these thiols to the disulfide form. Given that channel gating is a dynamic reversible rapid process, it is likely that a shift in the electron density within the protein, induced by addition of a channel modulator, may be responsible for the action of these channel activators (electron acceptors) or channel inhibitors (electron donors). All of the above observations suggest that the mechanism underlying release of $\mathrm{Ca}^{2+}$ via the RyR involves the withdrawal of electrons from a site within the RyR, and that the closing down of the CRC may involve an increase in the electron density within this critical region.

The methods developed in this paper to assay for the electron donor versus acceptor properties of various CRC modulators are similar to those used in previous studies in which reagents that modify $\mathrm{Na}^{+}$and $\mathrm{Ca}^{2+}$ channels were examined $(17,20)$, and to a recent study in which ryanodine was shown to act as an electron acceptor using flash photolysis techniques (18). However, this is the first time these types of assays have been carried out in an aerobic environment. By including a final electron acceptor, such as NBD-Cl or XTT, we were able to monitor superoxide generated in this light dependent reaction. CRC activators tested (caffeine, doxorubicin, mitoxanthrone, cystine, GSSG, and diamide) decreased superoxide concentrations, indicating their action as electron acceptors. However, CRC inhibitors tested (tetracaine, procaine, docosahexaenoic acid, GSH, and cysteine) increased MB photobleaching, which demonstrated their electron donor activity. Cystine, GSSG, and diamide are known to oxidize sulfhydryl groups, while GSH and cysteine reduce disulfides. As expected, thiol oxidizing reagents were electron acceptors, and the reducing agents tested were electron donors. Doxorubicin and mitoxanthrone, both anthraquinones, which had been proposed to stimulate the $\mathrm{Ca}^{2+}$ release mechanism by oxidation of critical thiols, are both observed to act as weak electron acceptors at comparable concentrations to those used in transport assays (1). Doxorubicin has been shown to activate the SR CRC by sensitizing the release channel to activation at low $\mathrm{Ca}^{2+}$ concentrations in a manner similar to caffeine. In Fig. 2, it is shown that caffeine at millimolar concentrations also acts a weak electron acceptor.

The chemical diversity of compounds that activate or inhibit the $\mathrm{Ca}^{2+}$ release mechanism is quite striking. We propose here, for the first time, a common mechanism by which these compounds appear to modify channel function. Their binding sites on the ryanodine receptor may be distinct and different, but common to many activators is their electron acceptor property, and common to many channel inhibitors tested is their ability to donate electrons. Implicit to this observation is that the RyR must also contain a mechanism for funneling electrons from distinct binding sites to a common site or sites in which channel function is controlled. The ability of proteins to transfer electrons from a donor to an acceptor separated by tens of angstroms is well documented (35). When thiol reducing agents such as GSH or cysteine are added, protein disulfides are reduced to thiols and inhibition of the CRC occurs (43). Conversely, when thiol oxidizing reagents, such as GSSG, cystine, or diamide are added, the CRC is activated and thiols are oxidized to disulfides (43). The thiol/disulfide balance is changed when thiol reducing or oxidizing reagents are added. However, the decrease in CRC activity induced by addition of tetracaine (an electron donor) can be reversed by perfusion of the buffer in contact with the channel (42). It seems likely that when tetracaine or other non-thiol channel inhibitors reversibly interact with the ryanodine receptor they form a charge transfer complex (3) which results in a transient redistribution of the local electron density within the RyR. This can be considered an example of a "weak redox interaction". When the solution is changed and the tetracaine is removed from the receptor, the electron density redistributes back to the state before the addition of tetracaine, and hence the effect of tetracaine is reversed. If the CRC opens and closes by shifting the local redox environment between more oxidized and reduced states, then one might expect that channel activators, such as caffeine, and channel inhibitors, such as tetracaine, would compete with each other, attempting to oxidize or reduce common redox active thiol pairs. Because of the large structural differences between tetracaine and caffeine, it is unlikely that they bind to the same site(s) on the RyR. However, they appear to share a common site of action (Fig. 7). The data presented suggest that caffeine reverses the inhibitory effect of the electron donor tetracaine by withdrawing electrons from a common site of action.

The effects of caffeine and tetracaine on the rate of CPM fluorescence development also indicate a competitive interaction. Millimolar concentrations of caffeine slow down the rate at which CPM interacts with hyperreactive thiols associated with RyR1, while low micromolar concentrations of 
tetracaine, in the presence of caffeine enhances the rate at which CPM interacts.

This competitive model is further supported by the data presented in Fig. 9, in which it is observed that tetracaine shifts the redox potential of hyperreactive thiols to more positive values, and significantly increases the number of CPMlabeled thiols on the RyR1. In contrast, caffeine shifts the redox potential to more negative values and decreases the number of reactive thiols. Given the large change in the number of reactive thiols upon addition of caffeine and tetracaine, and the corresponding changes in the redox potential of these reactive thiols, it appears as if changes in SH/S-S balance are caused by oxidation/reduction reactions. Some of these changes may also be due to conformational changes resulting from the opening/closing of the CRC. Not only does tetracaine donate electrons to dye cation radicals, as shown in Fig. 5 , but it also donates electrons to hyperreactive thiols on the RyR1, favoring the reduced state of the receptor. In a similar manner, caffeine accepts electrons from dye anion radicals (Fig. 2), and accepts electrons from RyR1, which favors the oxidized state of these reactive thiols.

In order for a channel modulator to affect function of a target protein, it must first bind to, then exchange electrons with the target protein. It is somewhat surprising how good of a correlation exists between the ability to donate or accept electrons in model photochemical reactions, and the ability to modulate channel activity. Electron acceptor activity was clearly evident with caffeine at 1-2 $\mathrm{m} M$ (Fig. 2), with doxorubicin and mitoxanthrone at 10-40 $\mu M$ (Fig. 3), while electron donor activity was observed with DHA at $400 \mu M$ (Fig. 5), and the local anesthetics tetracaine and procaine at $\sim 50 \mu M$. The similarity between the concentrations of these channel modulators that affect function and the concentrations that display electron donor/acceptor properties in the assays carried out with the excited dye radicals is quite evident. It appears as if the primary factor that determines the effectiveness of these drugs in modulating function is not determined only by the binding affinity, but more by the ability of these drugs to exchange electrons with the RyR protein. Conversely, a reagent can be an excellent electron acceptor or donor. However, if it does not bind to the RyR, it clearly will not affect channel activity.

Thiol oxidizing reagents such as $\mathrm{H}_{2} \mathrm{O}_{2}$, and $\mathrm{HOCl}$, activate the RyR at low concentrations and inactivate the RyR at high concentrations $(8,9)$. This biphasic action on ryanodine binding and channel activity can only be reversed by the addition of a thiol reducing agent. The inactivation observed at high concentrations of oxidizing reagents has been ascribed to the oxidation of less reactive thiols $(5,32)$. In a similar manner, many non-thiol channel activators, including $\mathrm{Ca}^{2+}$ and ryanodine show a biphasic concentration dependence. At micromolar concentrations, $\mathrm{Ca}^{2+}$ activates the RyR, while at millimolar concentrations, $\mathrm{Ca}^{2+}$ inhibits the $\mathrm{CRC}$ in a manner similar to thiol oxidizing reagents. It is tempting to speculate that high concentrations of $\mathrm{Ca}^{2+}$ or other channel activators, over-oxidize RyR thiols, and as a result close down the CRC.

In contrast to reagents that chemically oxidize thiols, the non-thiol reagents at low and moderate concentrations modify the release channel in a reversible manner. In this paper, we postulate that non-thiol channel modulators form a charge transfer complex, and we demonstrate that they shift the $\mathrm{SH} / \mathrm{S}-\mathrm{S}$ balance of reactive thiols on the CRC. While thiol reagents chemically react with the RyR thiols producing a long-lasting effect, non-thiol channel modulators shift the $\mathrm{SH} / \mathrm{S}-\mathrm{S}$ balance in a reversible manner-their effects last only as long as they remain bound to the RyR.

It is important to note that the proposed mechanism in which RyR activators are electron acceptors, and channel inhibitors are electron donors is not unique to the $\mathrm{Ca}^{2+}$ release channel from SR. Inhibitors of the L-type $\mathrm{Ca}^{2+}$ channel (nifedipine, verapamil, and diltiazem) have been shown to act as electron donors, while L-type channel activators such as Bay K 8644 acts as an electron acceptor (20). Local anesthetics, antiarrhythmics, and some anticonvulsants, which inhibit sodium channels, acted as electron donors in reactions with free radicals, while the sodium channel "agonists": veratridine, $\mathrm{N}$-bromosuccinimide, and chloramine- $\mathrm{T}$ all behaved as electron acceptors, despite differences in chemical structures (17). It appears as if regulation of channel function by electron donors and acceptors is a common feature of other transport proteins. A promising approach in the design of new channel regulators is to either provide new drugs with electron donor/acceptor properties or to alter existing donor/acceptor properties by appropriate chemical modifications.

The mechanism by which the regulating action is transferred from the binding site of the modulator to the channel gating is not clear. Interactions over long distances are common to many biological enzymes. In the case of the RyR, the binding sites associated with Imperatoxin A, calmodulin, and the FK506 binding protein are all on the cytoplasmic region of the RyR1, far from the transmembrane portion of the channel $(\sim 11 \mathrm{~nm})$ (26). In spite of the large distance between these sites, and the pore of the CRC, no conformational changes have been resolved at the spatial resolution available. In contrast, the conformation of the cardiac receptor, RyR2, differs considerably when it is depleted of FKBP12.6 in both the transmembrane and in the clamp structure region (30). An alternative to a conformational model for these interactions over relatively long distances is a model in which electrons are exchanged over large distances. The binding of a channel activator or inhibitor results in the formation of a charge transfer complex, and in a shift of the electron density, which propagates from the binding site to the regulatory center, where the $\mathrm{SH} / \mathrm{S}-\mathrm{S}$ balance is altered. This is likely to result in conformational changes with subsequent changes in channel gating. This model does not preclude conformational changes at intermediate steps in this process.

\section{ACKNOWLEDGMENTS}

This work was supported by the National Institute of Arthritis and Musculoskeletal and Skin Diseases (R01-AR48911) to JJA and Portland State University to BSM.

\section{ABBREVIATIONS}

CPM, 7-diethylamino-3-(4'-maleimidylphenyl)-4-methylcoumarin; CRC, calcium release channel; DHA, docosahexaenoic acid; DHPR, dihydropyridine receptor; GSH, 
reduced glutathione; GSSG, oxidized glutathione; HSR, heavy sarcoplasmic reticulum; NBD-Cl , 4-chloro-7-nitrobenzo-2-oxa-1,3-diazole; RyR1, ryanodine receptor type 1 from skeletal muscle; RyR2, ryanodine receptor type 2 from cardiac muscle; SR, sarcoplasmic reticulum; XTT, (2,3-bis(2methoxy-4-nitro-5-sulphophenyl)-5-[(phenylamino)carbonyl]-2H-tetrazolium hydroxide.

\section{REFERENCES}

1. Abramson JJ, Buck E, Salama G, Casida JE, and Pessah IN Mechanism of anthraquinone-induced calcium release from skeletal muscle sarcoplasmic reticulum. $J$ Biol Chem 263: $18750-18758,1988$.

2. Abramson JJ, Milne S, Buck E, and Pessah IN. Porphyrin induced calcium release from skeletal muscle sarcoplasmic reticulum Arch Biochem Biophys 301: 396-403, 1993.

3. Castleman AW Jr, Zhong Q, and Hurley SM. Femtochemistry uncovers the nature of electron transfer reactions. Proc Natl Acad Sci USA 96: 4219-4220, 1999.

4. Cheong E, Tumbev V, Abramson J, Salama G, and Stoyanovsky DA. Nitroxyl triggers $\mathrm{Ca} 2+$ release from skeletal and cardiac sarcoplasmic reticulum by oxidizing ryanodine receptors. $\mathrm{Cell} \mathrm{Cal}-$ cium 37: 87-96, 2005.

5. Dulhunty A, Haarmann C, Green D, and Hart J. How many cysteine residues regulate ryanodine receptor channel activity? Antioxid Redox Signal 2: 27-34, 2000.

6. Eu JP, Sun J, Xu L, Stamler JS, and Meissner G. The skeletal muscle calcium release channel: coupled $\mathrm{O} 2$ sensor and $\mathrm{NO}$ signaling functions. Cell 102: 499-509, 2000.

7. Fabiato A. Calcium-induced release of calcium from the cardiac sarcoplasmic reticulum Am J Physiol 245: C1-14; 1983

8. Favero TG, Webb J, Papiez M, Fisher E, Trippichio RJ, Broide M, and Abramson JJ. Hypochlorous acid modifies calcium release channel function from skeletal muscle sarcoplasmic reticulum. $J$ Appl Physiol 94: 1387-1394; 2003.

9. Favero TG, Zable AC, and Abramson JJ. Hydrogen peroxide stimulates the $\mathrm{Ca} 2+$ release channel from skeletal muscle sarcoplasmic reticulum. J Biol Chem 270: 25557-25563; 1995.

10. Favero TG, Zable AC, Colter D, and Abramson JJ. Lactate inhibits $\mathrm{Ca}(2+)$-activated $\mathrm{Ca}(2+)$-channel activity from skeletal muscle sarcoplasmic reticulum. J Appl Phvsiol 82: 447-452; 1997.

11. Feng W, Liu G, Xia R, Abramson JJ, and Pessah IN. Site-selective modification of hyperreactive cysteines of ryanodine receptor complex by quinones. Mol Pharmacol 55: 821-831; 1999.

12. Hess P, Lansman JB, and Tsien RW. Different modes of Ca channel gating behaviour favoured by dihydropyridine $\mathrm{Ca}$ agonists and antagonists. Nature 311: 538-544; 1984.

13. Honen BN, Saint DA, and Laver DR. Suppression of calcium sparks in rat ventricular myocytes and direct inhibition of sheep cardiac RyR channels by EPA, DHA and oleic acid. J Membr Biol 196: 95-103; 2003

14. Jayaraman $\mathrm{T}$, Brillantes AM, Timerman AP, Fleischer $\mathrm{S}$, Erdjument-Bromage H, Tempst P, and Marks AR. FK506 binding protein associated with the calcium release channel (ryanodine receptor) J Biol Chem 267: 9474-9477; 1992.

15. Liu G, Abramson JJ, Zable AC, and Pessah IN. Direct evidence for the existence and functional role of hyperreactive sulfhydryls on the ryanodine receptor-triadin complex selectively labeled by the coumarin maleimide 7-diethylamino-3-(4'-maleimidylphenyl)-4methylcoumarin. Mol Pharmacol 45:189-200; 1994.

16. MacLennan DH. Purification and properties of an adenosine triphosphatase from sarcoplasmic reticulum. J Biol Chem 245: 4508-4518; 1970.

17. Marinov BS. Na+ channel antagonists act as electron donors while agonists act as electron acceptors with free radicals. FEBS Lett 191: 159-162; 1985
18. Marinov BS, Bend EG, and Abramson JJ. Reactions with dye free radicals reveal weak redox properties of drugs Photochem Photobiol 2006.

19. Marinov BS and Evtodienko JV. Estimation of redox properties of chemical compounds by their reactions with free radicals. Anal Biochem 220: 154-159; 1994.

20. Marinov BS and Saxon ME. Dihydropyridine $\mathrm{Ca} 2+$ agonists and channel blockers interact in the opposite manner with photogenerated unpaired electrons. FEBS Lett 186: 251-254; 1985.

21. Menshikova EV and Salama G. Reactive disulfides elevate cytosolic free $\mathrm{Ca} 2+$ in cardiomyocytes by oxidizing regulatory thiols on ryanodine receptors (RyRs). Circulation 98: 805; 1998.

22. Olojo RO, Xia RH, and Abramson JJ. Spectrophotometric and fluorometric assay of superoxide ion using 4-chloro-7-nitrobenzo-2oxa-1,3-diazole. Anal Biochem 339: 338-344; 2005.

23. Pessah IN, Stambuk RA, and Casida JE. Ca2+-activated ryanodine binding: mechanisms of sensitivity and intensity modulation by $\mathrm{Mg} 2+$, caffeine, and adenine nucleotides. Mol Pharmacol 31: 232-238; 1987.

24. Rousseau E, Ladine J, Liu QY, and Meissner G. Activation of the $\mathrm{Ca} 2+$ release channel of skeletal muscle sarcoplasmic reticulum by caffeine and related compounds. Arch Biochem Biophys 267: 75-86; 1988

25. Salama $\mathrm{G}$ and Abramson J. Silver ions trigger $\mathrm{Ca} 2+$ release by acting at the apparent physiological release site in sarcoplasmic reticulum. J Biol Chem 259: 13363-13369; 1984.

26. Samso M, Trujillo R, Gurrola GB, Valdivia HH, and Wagenknecht $\mathrm{T}$. Three-dimensional location of the imperatoxin A binding site on the ryanodine receptor. J Cell Biol 146: 493-499; 1999.

27. Schafer FQ and Buettner GR. Redox environment of the cell as viewed through the redox state of the glutathione disulfide/glutathione couple. Free Radic Biol Med 30: 1191-1212; 2001.

28. Schaffner W and Weissmann C. A rapid, sensitive, and specific method for the determination of protein in dilute solution. Anal Biochem 56: 502-514; 1973.

29. Schneider MF and Chandler WK. Voltage dependent charge movement of skeletal muscle: a possible step in excitation-contraction coupling. Nature 242: 244-246; 1973.

30. Sharma MR, Jeyakumar LH, Fleischer S, and Wagenknecht T. Three-dimensional visualization of FKBP12.6 binding to an open conformation of cardiac ryanodine receptor. Biophys $J$ 90: $164-172 ; 2006$

31. Stoyanovsky D, Murphy T, Anno PR, Kim YM, and Salama G. Nitric oxide activates skeletal and cardiac ryanodine receptors. Cell Calcium 21: 19-29; 1997.

32. Sun J, Xin C, Eu JP, Stamler JS, and Meissner G. Cysteine-3635 is responsible for skeletal muscle ryanodine receptor modulation by NO. Proc Natl Acad Sci USA 98: 11158-11162; 2001.

33. Sutherland MW and Learmonth BA. The tetrazolium dyes MTS and XTT provide new quantitative assays for superoxide and superoxide dismutase. Free Radic Res 27: 283-289; 1997.

34. Takeshima H, Nishimura S, Matsumoto T, Ishida H, Kangawa K, Minamino N, Matsuo H, Ueda M, Hanaoka M, and Hirose T. Primary structure and expression from complementary DNA of skeletal muscle ryanodine receptor. Nature 339: 439-445; 1989.

35. Tezcan FA, Crane BR, Winkler JR, and Gray HB. Electron tunneling in protein crystals. Proc Natl Acad Sci USA 98: 5002-5006; 2001.

36. Trimm JL, Salama G, and Abramson JJ. Sulfhydryl oxidation induces rapid calcium release from sarcoplasmic reticulum vesicles. J Biol Chem 261: 16092-16098; 1986.

37. Voss AA, Lango J, Ernst-Russell M, Morin D, and Pessah IN. Identification of hyperreactive cysteines within ryanodine receptor type 1 by mass spectrometry. J Biol Chem 279: 34514-34520; 2004.

38. Weber A. The mechanism of the action of caffeine on sarcoplasmic reticulum. J Gen Physiol 52: 760-772; 1968.

39. West DJ, Smith EC, and Williams AJ. A novel and rapid approach to isolating functional ryanodine receptors 1. Biochem Biophys Res Commun 294: 402-407; 2002. 
40. Xia R, Stangler T, and Abramson JJ. Skeletal muscle ryanodine receptor is a redox sensor with a well defined redox potential that is sensitive to channel modulators. $J$ Biol Chem 275: 36556-36561; 2000.

41. Xia R, Webb JA, Gnall LL, Cutler K, and Abramson JJ. Skeletal muscle sarcoplasmic reticulum contains a NADH-dependent oxidase that generates superoxide. Am J Physiol Cell Physiol 285: C215-C221; 2003.

42. Xu L, Jones R, and Meissner G. Effects of local anesthetics on single channel behavior of skeletal muscle calcium release channel. J Gen Physiol 101: 207-233; 1993.

43. Zable AC, Favero TG, and Abramson JJ. Glutathione modulates ryanodine receptor from skeletal muscle sarcoplasmic reticulum Evidence for redox regulation of the $\mathrm{Ca} 2+$ release mechanism. $J$ Biol Chem 272: 7069-7077; 1997.
Address reprint requests to:

Jonathan J. Abramson

Physics Department

Portland State University

P.O. Box 751

Portland, Oregon 97207

E-mail: abramsonj@pdx.edu

Date of first submission to ARS Central, August 25, 2006; date of final revised submission, December 15, 2006; date of acceptance, January 6, 2007. 


\section{This article has been cited by:}

1. Derek R. Laver, Dirk F. vanHelden. 2011. Three independent mechanisms contribute to tetracaine inhibition of cardiac calcium release channels. Journal of Molecular and Cellular Cardiology . [CrossRef]

2. Scott K. Powers, Li Li Ji, Andreas N. Kavazis, Malcolm J. JacksonReactive Oxygen Species: Impact on Skeletal Muscle . [CrossRef]

3. Hilmi B. Kandilci, Erkan Tuncay, Esma N. Zeydanli, Nazli N. Sozmen, Belma Turan. 2011. Age-related regulation of excitation-contraction coupling in rat heart. Journal of Physiology and Biochemistry . [CrossRef]

4. Gerhard MeissnerRegulation of Ryanodine Receptor Ion Channels Through Posttranslational Modifications 66, 91-113. [CrossRef]

5. M. J. Jurynec, R. Xia, J. J. Mackrill, D. Gunther, T. Crawford, K. M. Flanigan, J. J. Abramson, M. T. Howard, D. J. Grunwald. 2008. Selenoprotein $\mathrm{N}$ is required for ryanodine receptor calcium release channel activity in human and zebrafish muscle. Proceedings of the National Academy of Sciences 105:34, 12485-12490. [CrossRef] 